\title{
Relaçôes de gênero entre familiares cuidadores de crianças e adolescentes de serviços de saúde mental
}

I ' Camila Junqueira Muylaert, 2 Patricia Santos de Souza Delfini, ${ }^{3}$ Alberto Olavo Advincula Reis I

Resumo: O conceito de gênero afirma desigualdades construídas socialmente entre homens e mulheres. Este estudo visa descrever e discutir, a partir da perspectiva das teorias de gênero, os lugares dos responsáveis familiares na provisão de cuidados e no sustento material de crianças e adolescentes usuários de Centros de Atenção Psicossocial Infantojuvenil (CAPSi). Trata-se de uma investigação descritiva, de corte transversal, realizada em 19 unidades de CAPSi no estado de São Paulo em 2009. Os dados foram coletados de uma amostra de 921 prontuários, submetidos a tratamento estatístico descritivo simples. A mãe é a principal responsável pelo cuidado em $56,9 \%(\mathrm{~N}=517)$ dos casos, seguidas pelos avós 7,8\%(N=71) e pelo pai em 2,5\%(N=23). O pai é o principal responsável pela renda familiar, em 20,3\%(N=185) dos casos, seguido pela mãe $8,9 \%(\mathrm{~N}=81)$. Grande parte dos prontuários não possui registro sobre este aspecto (49,2\%). A mulher se mantém como principal cuidadora, mesmo em casos em que ela é responsável pela renda. Ressalta-se a importância da mãe e da mulher no cuidado aos usuários dos CAPSis, demonstrando a hegemonia da tradicional noção do feminino como lugar do cuidado. O viés de gênero atravessa o campo da saúde mental e, dada sua relevância, deve ser considerado na atenção à população.

> Palavras-chave: saúde mental; identidade de gênero; cuidado infantil; família; adolescente.

\author{
1 Faculdade de Saúde Pública, \\ Universidade de São Paulo, \\ Saúde Materno-Infantil. \\ São Paulo-SP, Brasil. \\ Endereço eletrônico: \\ camilajmuylaert@usp.br \\ 2 Faculdade de Saúde Pública, \\ Universidade de São Paulo, \\ Saúde Materno-Infantil. \\ São Paulo-SP, Brasil. \\ Endereço eletrônico: \\ patriciadelfini@gmail.com \\ ${ }^{3}$ Faculdade de Saúde Pública \\ Universidade de São Paulo, \\ Saúde Materno-Infantil. \\ São Paulo-SP, Brasil. \\ Endereço eletrônico: \\ albereis@usp.br
}

Recebido em: 15/06/2014 Aprovado em: 28/09/2014 
A noção de cuidado tem permeado o pensamento presente em grande parte dos textos voltados à saúde pública e, desta feita, orientado muitas das ações deste campo. No âmbito da saúde mental brasileira, o cuidado vem sendo amplamente debatido, principalmente a partir da Reforma Psiquiátrica, que representa importante momento de mudança do paradigma doença-cura até então aplicado às doenças mentais. A ênfase não é mais dada ao tratamento da doença e seus sintomas, como na prática hospitalocêntrica, mas ao cuidado de pessoas concretas em sua relação com o meio. A ideia de tratamento associada à cura de doenças encontra-se amiúde substituída pela de cuidado voltado ao sofrimento. Essas substituições indicam transformação de certos paradigmas presentes em diversas práticas e disciplinas de saúde.

O termo "cuidado", embora antigo, em sua atual significação emergiu do solo da psicanálise e daí espraiou-se para o âmbito de diversas ações e compreensões do campo da saúde pública, confirmando o papel cada vez mais relevante então desempenhado pelas ciências humanas. Sua acepção não é, todavia, uniforme nem unívoca. No corpo desta investigação, foi adotada e discutida a noção de cuidado tal como ela aparece no desenvolvimento das formulações psicanalíticas de D. Winnicott. No âmbito da saúde mental pública, a saber, no bojo das proposições da Reforma Psiquiátrica, em particular, essa noção encontrou seu lugar estratégico na medida em que as ações preconizadas passaram a se apoiar fundamentalmente não mais na cura de transtornos mentais, mas na atenção voltada ao sofrimento psíquico, tendo como perspectiva a inclusão social dos excluídos.

A noção de cuidado assume, nesta perspectiva, papel de grande relevância quando se tem em alça de mira a população infanto-juvenil em função de suas características de desenvolvimento e crescimento dependentes. De acordo com diversas correntes teóricas, a prática de cuidado não é distribuída de modo homogêneo nas profissões de saúde nem tampouco entre as pessoas que assumem responsabilidades tutelares em relação à criança e ao adolescente, cabendo seu exercício muito mais ao gênero feminino do que ao masculino.

A importância alocada aos estudos baseados na perspectiva de gênero teve seu início desde que o termo "gênero" passou a ser usado pelas feministas americanas como uma maneira de se referir à organização social da relação entre os sexos. Mais especificamente, o conceito de gênero também pode ser definido como 
um conjunto de relações construídas pela cultura que, usando constituições biológicas, afirma as desigualdades entre homens e mulheres. Assim, a partir da anatomia, separa-se o lugar social das mulheres e dos homens (SCOTT, 1995). Segundo Heilborn (2003), o conceito de gênero existe para distinguir a dimensão biológica da social. Nesse sentido, tem-se que há machos e fêmeas na espécie humana, mas ser homem e ser mulher é uma distinção realizada pela cultura.

A introdução da noção de gênero permitiu que se associasse sexo à natureza, de um lado, e gênero à cultura, de outro lado; muito embora alguns autores, tais como Laqueur (1990), postularem que a própria natureza do sexo deva ser histórica e culturalmente relativizada. Laqueur (1990) discute essa ideia ilustrando historicamente que as diferenciaçōes e atribuições de papéis masculinos e femininos se deram quando se pensava haver um único sexo e as mulheres serem consideradas homens que não se desenvolveram completamente. De acordo com esse autor, foi apenas por volta do início do século XIX que surgiu o modelo de dois sexos opostos: o masculino e feminino. A construção desse novo modelo de sexos opostos decorreu de necessidades ideológicas e não de avanços tecnológicos, para justificar as desigualdades exigidas pela política e pela economia da ordem burguesa dominante, entre homens e mulheres com fundamentos em desigualdades naturais. Dessa forma, não só gênero seria atribuível a pautas sociais, mas também a própria noção distintiva de sexo.

Corroborando essa concepção, Moore (1997) indica que tanto o sexo como o gênero devem ser compreendidos como construçôes sociais. Assim, ela observa que em diferentes culturas, as diferenças biológicas são vistas de formas distintas, de modo que o binarismo "homem/mulher" não é fixo e natural - por exemplo, em muitas sociedades se acredita que as pessoas são feitas de partes ou substâncias femininas e masculinas.

Butler (2003), que é considerada uma autora pós-construcionista e bastante radical, propõe que somos inseridos em um gênero desde nosso nascimento até a morte. Propõe, ainda, a superação do modelo binário e opositor das categorias "mulher" e "homem". Para ela, as possibilidades e variabilidades de gênero seriam infinitas. Em sua teoria, a autora indica que gênero é uma imitação que persiste ao longo do tempo, de modo que passa a ser vista como natural do corpo.

Nas abordagens construcionistas, de modo geral, não se pode definir o natural quando nos referimos aos seres humanos; entende-se que o homem constrói a si 
próprio e a sua realidade. Em oposição, a noção de gênero, nas teorias essencialistas, defende que ser homem ou mulher dependeria de nossa constituição biológica, pois haveria uma essência humana determinada biologicamente.

Para Pirard, V. (2006), Zaccai-Reyners (2006) e Gilligan (1982), uma das dimensões éticas e morais do feminino se esteia na provisão de cuidados, que, por sua vez, se assenta na noção de desvelo ou solicitude, enquanto que para o gênero masculino tais dimensões se apoiam, sobretudo, na ideia de justiça. A noção de gênero desses autores, assim como a de Winnicott, se revelou particularmente fecunda para os objetivos deste estudo; assim, os utilizaremos tendo em vista que a moral masculina e feminina são construções sociais e não naturais ou determinadas biologicamente.

Esse tema mostra-se relevante, uma vez que há importantes transformaçôes ocorrendo nesse campo: "é a lenta degradação e contestação do patriarcado que tem permitido pensá-lo - ou seja, estamos a viver um período de transição histórica, de transformação na hegemonia, em que os conflitos, 'ruídos' e disputas que sempre existiram se tornaram mais audíveis e perturbadores" (ALMEIDA, 1996, p. 164). Apesar dessas transformações, "ainda hoje reproduz-se nas relações de gênero e familiares, uma delimitação clara de papéis e modelos” (LYRA; MEDRADO, 2000, p. 145).

Além disso, são escassas as pesquisas que envolvem relações de gênero, saúde mental e cuidado, apesar de haver alguns estudos que discutem relações de gênero entre usuários de saúde mental (SANTOS, 2009; REIS et al., 2012; LUDERMIR, 2008), assim como os que relacionam loucura ao feminino (FACCHINETTI; RIBEIRO; MUÑOZ, 2008; OLIVEIRA, 1996; VACARO JS, 2011).

Tendo em vista tais considerações, o trabalho vem descrever e discutir, a partir da perspectiva da noção de gênero, as ações de cuidado, assim como coabitação e sustento material desempenhados no âmbito familiar, por homens e mulheres responsáveis por crianças e adolescentes atendidas nos CAPSis do estado de São Paulo. Não constituiu objeto de nosso interesse no desenho inicial do estudo e no processo de coleta de dados as relações de gênero entre os responsáveis por crianças e adolescentes atendidas nos CAPSis; entretanto, em função de uma situação emergente do próprio processo investigativo, consideramos que seria interessante a análise do tema. 
Investigação descritiva, de corte transversal, realizada em 19 unidades de Centros de Atenção Psicossocial Infanto-juvenil (CAPSi) no estado de São Paulo, no ano de 2009 (REIS et al., 2012). Os dados aqui apresentados são parte da pesquisa "Caracterização sociodemográfica e epidemiológica da população atendida nos Centros de Atenção Psicossocial Infanto-juvenil do estado de São Paulo”, realizada com o apoio financeiro da Fundação de Amparo à Pesquisa do Estado de São Paulo (FAPESP), projeto 2006/06902-2.

A população nacional estimada pelo IBGE em 2007 era de 183.987.291 habitantes, sendo que o estado de São Paulo concentra aproximadamente 22\% dessa população, ou seja, 41.633.802 habitantes (SEADE, 2009). Desse total, 12.949.224 são crianças e adolescentes de até 19 anos de idade, o que representa $31,1 \%$ da população do estado. Considerando a expectativa de cobertura de um CAPSi para cada 200.000 habitantes indicada pela Portaria no 336/02, há uma clara insuficiência dos serviços.

O critério de escolha das unidades foi que estivessem habilitados pelo Cadastro Nacional de Saúde (CNS) até outubro de 2006, ou seja, um ano antes do início do desenvolvimento da pesquisa. Assim, existiam naquele momento 69 CAPSis no país, sendo 20 no estado de São Paulo, as quais foram incluídas na pesquisa (DATASUS, 2007). Uma unidade prestou-se aos testes da pesquisa, de modo que fizeram parte da investigação 19 unidades de serviço de diferentes municípios, sendo sete do município de São Paulo e 13 do interior do estado.

Foi realizado levantamento de todos os prontuários ativos nos CAPSis pesquisados, totalizando 2.216 prontuários. Desse total, foi feito um sorteio aleatório randômico, e obteve-se uma amostra de 921 prontuários de crianças e adolescentes, baseando-se na prevalência de 21\% de problema de saúde mental na infância e na adolescência no Brasil (MELLO; MELLO; KOHN, 2007), acrescida de 30\% de perdas, com nível de significância de $95 \%$ e margem de erro de 3\%. Outro critério de seleção foi adicionado, com a condição de que todos os prontuários pesquisados estivessem ativos há no mínimo três meses da data da coleta dos dados, que ocorreu no período de setembro de 2008 a fevereiro de 2009. Dos 921 prontuários estimados, foram validados 909, havendo perda de 1,3\%. Os dados foram codificados 
com auxílio do Programa de Banco de Dados EPI INFO 3.5.1 e submetidos a tratamento estatístico descritivo simples.

Foi utilizado um protocolo de pesquisa padronizado para extrair os dados dos prontuários, visando obter informações sociodemográficas, clínicas e epidemiológicas. São elas: 1) identificação do usuário; 2) moradia; 3) estrutura familiar; 4) escolaridade/ocupação; 5) histórico clínico e anamnese; 6) diagnóstico; 7) conduta; e 8) evolução. No presente artigo, serão discutidos dados referentes aos itens 2 e 3: moradia e estrutura familiar, incluindo informações sobre responsáveis pelo cuidado e responsáveis pela renda dessas crianças.

A pesquisa foi realizada conforme as normas que regulamentam pesquisas com seres humanos, contidas nas Resoluções nos 196/96 e 251/97 do Conselho Nacional de Saúde do Ministério da Saúde, e aprovada pelos Comitês de Ética em Pesquisa da Faculdade de Saúde Pública da Universidade de São Paulo e da Secretaria Municipal da Saúde de São Paulo.

\section{Resultados e discussão}

\section{Coabitação}

A tabela 1 mostra que $45,0 \%$ das crianças moram com a mãe e com o pai e 28,7\% moram somente com a mãe. Apenas 2,0\% moram somente com o pai. Os $24,3 \%$ restantes moram com outras pessoas que não o pai e/ou a mãe, havendo 53 usuários que moram com a avó, ou seja, 5,9\% dos sujeitos.

Tabela 1: Distribuição do número (n) e porcentagem (\%) do familiar responsável que habita com a criança/adolescente usuários dos CAPSi do Estado de São Paulo, São Paulo, 2009.

\begin{tabular}{lrr}
\hline Familiar & $\mathrm{n}$ & $\%$ \\
\hline Só Pai & 18 & 2,0 \\
Só Mãe & 261 & 28,7 \\
Pai e Mãe & 409 & 45,0 \\
Outros & 221 & 24,3 \\
\hline TOTAL & $\mathbf{9 0 9}$ & $\mathbf{1 0 0 , 0}$ \\
\hline
\end{tabular}

Fonte: Reis (2010). 
Assim, observa-se facilmente que a presença da mãe em relação às outras composições familiares possíveis de convivência domiciliar é altamente predominante. Além disso, esses dados parecem indicar a prevalência de uma estrutura familiar clássica, nuclear, formada pelo casal e filho(s). Embora essa estrutura prevaleça, o censo de 2010 (IBGE, 2010) indica que essa configuração familiar está em declínio, de 55,0\% em 1999 para 47,3\% em 2009.

Famílias que se organizam em convivências marcadas pela presença exclusiva da mãe aparecem em segundo lugar, o que vai ao encontro do verificado na situação observada na população brasileira: 17,4\% das famílias (IBGE, 2010).

\section{Cuidado e renda}

A mãe aparece como principal cuidadora em 56,9\% dos casos, os avós em $7,8 \%$ e o pai em 2,6\%, cabendo aos abrigos à responsabilidade por $2,1 \%$ de crianças e adolescentes sob seus cuidados. Os grupos "tio e tia", "mãe e outro parente" e "mãe e pai" aparecem, respectivamente, como responsáveis pelo cuidado em 1,9\%, 1,5\% e 1,5\% dos casos. A predominância de responsabilidade pelo cuidado recai sobre a mãe, refletindo o indicado na literatura (LE BLANC; WORMS, 2006) e se conjugando com dados relativos à coabitação mostrados neste estudo.

Tabela 2: Distribuição do número (n) e porcentagem (\%) dos usuários dos CAPSi do Estado de São Paulo segundo principal responsável pelo cuidado, São Paulo, 2009.

\begin{tabular}{ccc}
\hline Principal Responsável pelo Cuidado & $\mathrm{n}$ & $\%$ \\
\hline Mãe & 517 & $56,9 \%$ \\
Não Consta & 216 & $23,8 \%$ \\
Avós & 71 & $7,8 \%$ \\
Pai & 23 & $2,5 \%$ \\
Abrigo & 19 & $2,1 \%$ \\
Tía & 15 & $1,7 \%$ \\
Mãe e outro parente & 14 & $1,5 \%$ \\
Mãe e pai & 13 & $1,4 \%$ \\
Irmãos & 9 & $1,0 \%$ \\
Outros & 12 & $1,3 \%$ \\
Total & 909 & $100,0 \%$ \\
\hline
\end{tabular}

Fonte: Reis (2010). 
Em função da repartição de papéis familiares no âmbito das constelações familiares nucleares tradicionais, tal como aparenta ser a estrutura hegemônica das famílias dos usuários dos CAPSis do estado de São Paulo, tentou-se estabelecer algumas comparações que envolvessem a repartição dos papéis alocados no interior da família no que tange aos cuidados e renda.

No que se refere à informação sobre o principal responsável pela renda familiar, observamos que grande parte dos prontuários não possui qualquer registro sobre este aspecto (49,2\%). Essa expressiva ausência de dados se deve provavelmente à falta de padronização dos prontuários dos CAPSis ou descuro em seu preenchimento (REIS et al., 2009), bem como pode indicar um viés psicologizante nos modos de compreender e cuidar de pessoas em sofrimento psíquico, no qual informações de natureza socioeconômica seriam irrelevantes ou secundárias na composição do caso. Tal imprecisão nos dados impede a produção de informações mais decisivas e confiáveis sobre o item "principal responsável pela renda" de forma que ele passa ter aqui apenas valor indicativo.

Para Bertolli Filho (2006), os prontuários são peças preciosas que tornam viável a apreensão da memória da saúde, assim como são um núcleo documental potente e instrumento importante de reflexão sobre o comportamento humano. O autor aponta a dificuldade de historiadores da medicina em localizar documentos consistentes, sendo os arquivos prontuariais uma importante fonte de dados, mas que raras vezes são encontrados, e quando localizados, se mostram escassos em dados, números e restritos a períodos mais recentes.

Nos dados declarados, encontramos 20,3\% dos casos que têm como principal responsável pela renda o pai; em seguida, a mãe para $8,9 \%$ dos casos, e em 3,4\% dos casos ambos são mencionados. Além disso, outros familiares descritos como responsáveis pela renda, com mais de $1 \%$ dos casos, foram a avó e o padrasto, como se vê na tabela 3. A predominância masculina como principal responsável pela renda vai ao encontro do observado na população paulista que, segundo o Dieese (2009), tem o homem como principal responsável pela renda em 76,0\% das famílias. 
Tabela 3: Distribuição do número (n) e proporção (\%) dos usuários dos CAPSi do

Estado de São Paulo segundo principal responsável pela renda, São Paulo, 2009.

\begin{tabular}{lcc}
\hline Principal responsável pela renda & $\mathbf{n}$ & $\%$ \\
\hline Não consta & 447 & 49,2 \\
Pai & 185 & 20,3 \\
Outros & 83 & 9,1 \\
Mãe & 81 & 8,9 \\
Pai e mãe & 31 & 3,4 \\
Avó & 19 & 2,1 \\
Padrasto & 16 & 1,8 \\
Mãe e padrasto & 9 & 1,0 \\
Avô & 8 & 0,9 \\
Tios e tias & 7 & 0,8 \\
Outros familiares & 7 & 0,8 \\
Pai e outros familiares & 5 & 0,6 \\
Irmãos & 4 & 0,4 \\
Mãe e outros familiares & 4 & 0,4 \\
Mãe e tios (as) & 3 & 0,3 \\
\hline Total & 909 & 100,0 \\
\hline
\end{tabular}

Fonte: Reis (2009).

Quando se cruzam os dados referentes à "responsabilidade pela renda" e à "responsabilidade pelos cuidados" verifica-se que em $82,7 \%$ dos casos em que a mãe é a responsável pela renda da casa, ela também é a responsável pelo cuidado da criança. O mesmo acontece com a avó, que em $84,2 \%$ dos casos em que ela é a responsável pela renda, ela também o é pelo cuidado. Contrariamente a isso, em 93,5\% das famílias em que o pai é responsável pela renda familiar, ele não se posiciona como responsável pelo cuidado. Nessa situação, a função de cuidados é assumida pela mãe em $82,2 \%$ dos casos. Além disso, a mãe é a responsável mais frequente pelo cuidado da criança, independentemente de qual seja o familiar provedor da renda para a casa.

Os dados obtidos vêm ressaltar a grande importância da mulher no cotidiano e no cuidado dispensado aos usuários dos CAPSis. Nesse sentido, CAVALCANTE (2004), em pesquisa sobre a mulher brasileira nos espaços públicos e privados, indica que as mulheres se sentem sozinhas devido à falta de participação ou 
inexistência do pai na criação dos filhos, bem como na responsabilidade pela renda familiar. Há relevante produção literária que carreia interessante debate acerca da dimensão do feminino na provisão de cuidados baseando-se na noção de desvelo ou solicitude (SAILLANT, 1991; PAPERMAN; LAUGIER, 2005; LE BLANC; WORMS, 2006; PIRARD, V., 2006; BRUGËE, 2006; WORMS, 2006; LE BLANC, 2006; ZACCAI-REYNERS, 2006).

$\mathrm{O}$ ato de cuidar mobiliza uma forma de relação assimétrica com o outro verifica-se uma dissimetria entre o cuidador e aquele que é cuidado. Vale dizer que o cuidar é atravessado por dois grandes temas: de um lado, o do poder que cura, trata e alivia e/ou violenta; de outro, o do desvelo ou solicitude. Este último, o do desvelo, é localizado por Pirard, V. (2006) dentro de uma perspectiva que faz apelo a noções psicanalíticas originadas do solo winnicottiano, tais como a preocupação materna primária. $\mathrm{O}$ autor distancia-se, pois, da dialética hegeliana da dominação e da morte, mais evidenciada pela psicanálise lacaniana na tematização da relação do Eu com o Outro ou da perspectiva, também lacaniana, do "discurso médico" de Clavreul (1983), mas mesmo dentro dessas paragens há quem, como Soller (2005, p. 180), estime que:

[...] o cuidado é mais comumente pensado como apanágio da mãe. Quer ela se dedique a sustentar o corpo, quer se empenhe em ser para seu filho a mediadora da linguagem e de seus diversos efeitos, a um tempo castradores e erógenos, toda sua solicitude equivale a uma manifestação primeira de seu amor de mãe. Para o pai não se pode tratar-se de simplesmente reproduzir esses cuidados maternos. Ponhamos pois a seu encargo, com a função de sua presença, afirmada seja de que for junto à mãe, o cuidado simbólico: a transmissão do Nome, sempre crucial, porque acarreta a inscrição na cadeia das gerações e num desejo que não seja anônimo.

Pirard, V. (2006), ao desenvolver o tema da solicitude ou desvelo, estima que todo cuidar se insere numa relação de dependência. Nesse sentido, o que diferencia a posição de PIRARD, V. (2006) (da lacaniana, por exemplo) é que a autora entende que a relação de cuidado se fulcra não no desejo (o desejo do médico, por exemplo), mas na noção de necessidade (de alguém). Se o desejo é sempre objetal, considerando o objeto uma instância fantasiosa, tal como expressa o matema lacaniano do " $\mathrm{S}<>$ a", a necessidade é relacional, se organiza na interação e se torna mobilizadora de afetos.

O modelo do qual Pirard, V. (2006) irá derivar sua compreensão da dimensão relacional mobilizadora de afeto e fundadora do desvelo encontra-se presente na compreensão da disposição de mães para responder às necessidades do bebê 
à qual Winnicott (1993) denominou de "preocupação materna primária”. Essa

disposição não remete a nenhuma constituição natural da mulher tal como é suposto ou pressuposto por formas ideologizadas que se veem presentes em organizações familiares em que, sob efeitos de condições sociais, econômicas e micropolíticas, a distribuição do papel de provedor recai sobre o homem e o de cuidado sobre a mulher.

A disposição, configurada na "preocupação materna primária", de responder de maneira integral e plena às necessidades do bebê, refere-se propriamente a uma "crise" vivida e atravessada pela mãe quando se depara com inteira dependência de um ser que será seu bebê. Desse modo, o cuidado é visto como um trabalho que implica profundo remanejamento psíquico. De acordo com Winnicott (1993), a preocupação materna primária poderia ser comparado com um fenômeno psiquiátrico se não fosse normal. Diz o autor que a preocupação materna primária corresponde

[...] a uma condição psiquiátrica muito especial da mãe, acerca da qual eu diria o seguinte: esta condição gradualmente se desenvolve e se torna um estado de sensibilidade aumentada durante, e especialmente, no final da gravidez. Continua por algumas semanas depois do nascimento da criança; não sendo facilmente recordada, uma vez, tendo a mãe se recuperado dela (WINNICOTT, 1993, p. 121).

Granato e Aiello-Vaisberg (2002, p. 89) resumem muito adequadamente esse conceito:

[...] desde a gestação até as primeiras semanas após o parto, a mulher desenvolve o que chamou de preocupação materna primária. Esse conceito refere-se a um estado de funcionamento psíquico especial, caracterizado por uma sensibilidade aumentada, o qual possibilita que a mulher atenda às necessidades do bebê, ao identificar-se com ele, a partir de suas próprias experiências como bebê. Durante o período da dependência absoluta e fase de holding a mãe é capaz de sustentar, manejar e apresentar a realidade para o bebê de maneira sensível e constante, o que segundo Winnicott, requer empatia por parte da mãe, possibilitando a maturação do ego do bebê e, com isso, o bebê pode sentir que existe e vir a estabelecer relações objetais. É o que este autor chama de capacidade do indivíduo de "viver com". É importante mencionar que Winnicott entende não apenas o bebê como em estado de dependência, mas a própria a mãe, já que ela encontra-se identificada com o seu bebê, a fim de satisfazer suas necessidades que inicialmente são corporais, tornando-se cada vez mais necessidades do ego. Possivelmente, pela presença do estado de dependência e vulnerabilidade na mãe, o autor entenda que seja tão difícil e doloroso para as mães se separarem de seus bebês, podendo não acompanhar a rapidez com que os bebês precisam ficar separados delas. É a mãe devotada comum capaz de envolver-se emocionalmente com o bebê. 
Para Pirard, V. (2006, p. 80), "o cuidado, na medida em que envolve tanto o corpo quanto a vida psíquica, suscita produções imaginárias e representaçōes prototípicas ligadas ao médico, à enfermeira assim como gera representaçôes conectadas às figuras parentais da mãe ou da avó” (p.80). Além disso, o cuidado liga-se ao feminino por uma razão adicional que remete à distinção entre a moral masculina e a moral feminina. Para tanto, a autora, inspirando-se nas formulações feministas de Gilligan (1982), considera que, pelo viés da moral, a estrutura de cuidados pertence ao universo feminino.

Segundo Gilligan (1982), a moral masculina, fulcrada na ideia de justiça, compreende que o ser humano possui certos direitos básicos, universais, que determinam, por sua vez, o respeito ao direito dos outros. Dessa forma, a moral masculina atua no registro da justiça e da restrição. Diferentemente dela, a moral feminina assenta-se na ideia da responsabilidade em relação ao outro, o que determina que seu imperativo seja o cuidado para com o outro.

Bustamante e Trad (2005) discutem os papeis predefinidos socialmente na função do pai e da mãe nos cuidados do lar, sendo o homem responsável pela moral, pela respeitabilidade familiar, enquanto a mãe tem a responsabilidade pelo cuidado e pela manutenção da unidade do grupo, mesmo nos casos em que ela é provedora de recursos materiais na casa.

Oliveira e Roazzi (2007) afirmam que, historicamente, o espaço de atuação da mulher e do homem são distintos. À mulher cabe o espaço privado, sendo esta considerada frágil e "da casa" e sua honra se expressa pela fidelidade ao marido, pela reprodução e responsabilidade no desenvolvimento dos filhos. Já ao homem cabe o espaço público, e sua respeitabilidade advém da capacidade de provedor da família de alimentos e de respeito.

O fato da desvalorização dos trabalhos relacionados aos cuidados, lote de mulheres ou de pessoas desqualificadas sócio-profissionalmente, prender-se-ia à hegemonia masculina da moral de justiça e às suas consequências nos planos social, da hierarquização sócio-valorativa do trabalho e do político ou econômico e na provisão material da vida.

Outros "estudos de gênero aludem que a designação social da esfera pública de produção ao homem e a da esfera privada de reprodução e cuidado dos outros à mulher resulta na valorização diferenciada das responsabilidades, escolhas, hábitos e comportamentos de cada sexo" (REDE..., 2005, p. 14). Em posição 
diferente às de Gilligan (1982) e Pirard, V. (2006), a Rede Nacional Feminista de Saúde, Direitos Sexuais e Direitos Reprodutivos (2005, p. 14) estima que

[...] a naturalização dos trabalhos domésticos e reprodutivos (tarefas familiares e de cuidado de crianças, idosos e doentes) debilita a autoestima de mulheres e meninas; representa um dos principais obstáculos para o seu acesso e controle de bens e recursos e aumenta a sua vulnerabilidade ante a violência familiar e sexual.

Em nosso estudo, pudemos observar que entre as famílias de crianças e adolescentes de CAPSis, a tendência da mulher de ir para o mercado de trabalho não é acompanhada pela tendência do homem de cuidar da vida doméstica. Dessa forma, a mulher acumula duas tarefas, o que vem sendo considerado como "a dupla jornada feminina". Podemos aventar que essa situação repercuta no efeito de fixar a mulher em seu papel tradicional de cuidadora do lar, uma vez que nem sempre é possível conciliar a tarefa de ser responsável pela renda e pelo cuidado, principalmente quando se trata de crianças e adolescentes em sofrimento psíquico.

A dificuldade das mães em perceber, reconhecer e valorizar o cuidado oferecido pelos pais (CREPALDI et al., 2006) pode contribuir para a manutenção dos papéis tradicionais. Isso indica que a concepção de que a mulher nasce com um saber sobre cuidar, saber este que não pertence ao universo masculino, parece hegemônica e fortemente arraigada no imaginário social e cultural, embora se percebam sinais claros de que a tendência tradicional da mulher cuidar da casa e filhos e o homem do sustento financeiro familiar esteja em processo de transformação. ${ }^{1}$

\section{Considerações finais}

O estudo mostrou o papel hegemônico dos cuidados prodigados, no âmbito familiar, pelas mães e avós, à população infanto-juvenil atendida nos CAPSis do estado de São Paulo. Investigações sobre cuidadores familiares de usuários de serviços de saúde mental, sobretudo quando desenvolvidas à luz das teorias de gênero, são praticamente inexistentes na literatura. Por outro lado, nos estudos que se debruçam sobre a vida familiar, a mulher tende a ser a principal ou única informante (LYRA; MEDRADO, 2000; BUSTAMENTE; TRAD, 2005) a respeito do papel feminino e masculino tal como ele se distribui no interior da família. Em nossa pesquisa, ao usarmos os prontuários como fonte de dados, acreditamos ter evitado esse viés. 
Pudemos mostrar que a distribuição dos cuidados familiares voltados às crianças e adolescentes, usuários de CAPS, em intenso e/ou contínuo sofrimento psíquico, é bastante desigual, cabendo às figuras femininas tais encargos. Foi, contudo, interessante observar que a distribuição sexual de cuidados não corresponde inteiramenteà tradicional divisão de trabalho, de acordo com a qual caberia às mulheres a responsabilidade doméstica, e aos homens, o trabalho fora de casa e a provisão de bens materiais. Assim, quando são as mulheres as responsáveis pela manutenção material da família, sejam elas mães ou avós, elas também o são pelo cuidado em relação às crianças e adolescentes usuários de CAPSis. Quando o pai não desempenha função de manutenção, ele também não participa significativamente do cuidado a(o) filho(a). Tais indicações nos permitiram utilizar, de modo fecundo, os aportes teóricos de Gilligan e Pirard, entre outros, para elucidar a significação relativa da dimensão feminina do cuidado.

Por fim, é importante a conscientização, tanto da população de forma geral como de serviços de saúde, sobre a possibilidade de o cuidado ser exercido por ambos os sexos e não naturalizado como tarefa do universo feminino. A partir dessa reflexão, almejamos que se valorize a tarefa de cuidar de crianças e adolescentes, tanto no interior da família como no mercado de trabalho. Nos serviços de saúde mental, onde o cuidado é parte fundamental, espera-se que haja incentivo à participação de pessoas de ambos os sexos de forma ativa do tratamento de crianças e adolescentes, já que é fundamental a participação de figuras masculinas e femininas no desenvolvimento, crescimento e cuidado da criança e adolescente, assim como há uma tendência de todos trabalharem fora de casa.

\section{Referências}

ALMEIDA, M.V de. Gênero, Masculinidade e Poder: revendo um caso do sul de Portugal. Anuário Antropológico, Portugal, v. 95, p. 161-90, 1996.

BERTOLLI FILHO, C. Prontuários médicos: fonte para o estudo da história social da medicina e a enfermidade. História, Ciências, Saúde - Manguinhos. Rio de Janeiro, v. 3, n. 1, p. 173-180, 1996.

- Prontuários médicos e a memória da saúde brasileira. Memória e história da saúde

em São Paulo. Boletim do Instituto de Saúde. São Paulo, n. 38, p. 12-15, abr. 2006.

BRASIL. Ministério da Saúde. Coordenação Geral de Saúde Mental. Saúde mental no SUS: acesso ao tratamento e mudanças do modelo de atenção. Relatório de gestão 2003-2006. Brasília: Ministério da Saúde, 2007. 
BRUGERE, F. La sollicitude. La nouvelle donne affective des perspectives feministes, Esprit, p. 1-13, Janvier 2006.

BUSTAMANTE, V.; TRAD, L.A.B. Participação paterna no cuidado de crianças pequenas: um estudo etnográfico com famílias de camadas populares. Cad. Saúde Pública. Rio de Janeiro, v. 21, n. 6, p. 1865-1874, 2005.

BUTLER, J. Problemas de gênero: feminismo e subversão da identidade. Rio de Janeiro: Civilização Brasileira, 2003.

CAVALCANTE, A. Bastidores da pesquisa: revelações de identidades de gênero. In: VENTURINI, G.; RECAMAN, M.; OLIVEIRA, S. (Orgs.). A mulher brasileira nos espaços público e privado. São Paulo: Fundação Perseu Abramo, 2004. p. 183-190.

CLAVREUL, J. A ordem médica: poder e impotência do discurso médico. São Paulo: Brasiliense, 1983. $276 \mathrm{p}$.

CREPALDI, M.A. et al. A participação dos pais nos cuidados da criança, segundo a concepção de mães. Psicologia em Estudo. Maringá, v. 11, n. 3, p. 579-587, 2006.

DEPARTAMENTO INTERSINDICAL DE ESTATÍSTICA E ESTUDOS SOCIOECONÔMICOS. Características da família paulistana. Disponível em: http:// www.dieese.org.br/pof/pof2.xml. Acesso em: 11 nov. 2009.

FACCHINETTI, C.; RIBEIRO, A.; MUÑOZ, F. As insanas do Hospício Nacional de Alienados (1900-1939). História, Ciências, Saúde-Manguinhos, Rio de Janeiro, v. 15, sup., p. 231-242, 2008.

GILLIGAN, C. In a different voice: psychological theory and women's Development. Boston. Harvard University Press, 1982. 184 p.

GRANATO, T.M.M.; AIELLO-VAISBERG, T.M.J. A preocupação materna especial. Psicol. Clín. Rio de Janeiro, v. 14, n. 2, p. 87-91, 2002.

HEILBORN, M.L. Articulando gênero, sexo e sexualidade: diferenças na saúde. In: GOLDENBERG, P.; MARSIGLIA, R.M.G.; MARA, H.A.G. (Orgs.). O clássico e o novo: tendências, objetos e abordagens em ciências sociais e saúde. Rio de Janeiro: Fiocruz, 2003. p. 197-208.

INSTITUTO BRASILEIRO DE GEOGRAFIA E ESTATÍSTICA. População recenseada e estimada, segundo as Grandes Regiōes e as Unidades de Federação, 2007. Disponível em: <http://www.ibge.gov.br/home/estatistica/populacao/contagem2007/contagem_final/ tabela1_1.pdf> Acesso em: 11 nov. 2009.

Sintese de Indicadores Sociais: uma análise das condições de vida da população Brasileira, 2010. Rio de Janeiro: IBGE, 2010.

LAQUEUR, T. Making sex: body and gender from the Greeks to Freud. Boston: Harvard University Press, 1990. 313 p. 
LE BLANC, G. La vie psychique de la maladie. Esprit, p. 109-122, Janvier 2006.

LE BLANC, G.; WORMS, F. Les nouvelles figures du soin. Introduction. Esprit, p. 77-79, Janvier 2006.

LUDERMIR, A. Desigualdades de classe, gênero e saúde nas cidades. Physis: Revista de Saúde Coletiva, Rio de Janeiro, v. 18, n. 3, p. 451-67, 2008.

LYRA, J.; MEDRADO, B. Gênero e paternidade nas pesquisas demográficas: o viés científico. Estudos Feministas, v. 8, n. 1, p. 145-158, 2000.

MELlO, M.F.; MELlO, A.A.F.; KOHN, R. (Orgs.). Epidemiologia da Saúde Mental no Brasil. Porto Alegre: Artmed, 2007.

MOORE, H. Compreendendo sexo e gênero. In: INGOLD, T. (Org.). Companion Encyclopedia of Anthropology. London: Routledge, 1997.

OLIVEIRA, A.C.S. Mulher solta, mulher louca Maria Venuto, das horas de seus dias à tela de cinema. 1996. 195 p. Dissertação (Mestrado em Multimeios) - Instituto de Artes, Universidade Estadual de Campinas, São Paulo, 1996.

OLIVEIRA, A.B.; ROAZZI, A. A representação social da "doença dos nervos" entre os gêneros. Psicologia: teoria e pesquisa, v. 23, n. 1, p. 91-102, 2007.

PAPERMAN, P.; LAUGIER, S. Le souci des autres. Éthique et politique du care. Paris: Éditions de l'École des Hautes Etudes en Sciences Sociales, 2005. 349 p.

PIRARD, V. Qu'est ce qu'un soin? Pour une pragmatique non vertueuse des relation de soin. Espirit, p. 80-95, Janvier 2006.

REDE NACIONAL FEMINISTA DE SAÚDE, DIREITOS SEXUAIS E DIREITOS REPRODUTIVOS. Rede Feminista de Saúde Regional Rio Grande do Sul. Dossiê Violência de Gênero Contra Meninas. Violência doméstica ou intrafamiliar; exploração sexual e comercial; violência institucional por ação ou omissão. Porto Alegre, 2005.

REIS, A.O.A. et al. Cuidado, gênero e saúde mental. In: ROLIM NETO, M.L. et al. (Orgs.). Saúde Mental Coletiva: clínicas e vulnerabilidades. 1 ed. São Paulo: Schoba, 2012. p. $117-130$.

(Orgs.). As crianças e os adolescentes dos Centros de Atenção Psicossocial Infantojuvenil. São Paulo: Schoba, 2012.

. Prontuários, para que servem? Representação dos coordenadores de equipe dos CAPS a respeito do valor e da utilidade dos prontuários. Revista Brasileira do Crescimento e do Desenvolvimento Humano, v. 19, n. 3, p. 383-392, 2009.

SAILLANT, F. Les soins en péril: entre la nécessité et l'exclusion. Recherches féministes, v. 4, n. 1, 1991.

SANTOS, A. Articular saúde mental e relações de gênero: dar voz aos sujeitos silenciados. Ciência \& Saúde Coletiva, v. 4, n. 14, p. 1177-82, 2009. 
Estado de São Paulo, 2009. Disponível em: http://produtos.seade.gov.br/produtos/perfil_ estado/ Acesso em: 11 nov. 2009.

SCOTT, J. Gênero: uma categoria útil de análise histórica. Educação e realidade, v. 20, n. 2, p. 71-99, 1995.

SOLLER, C. O que Lacan dizia das mulheres. Rio de Janeiro: Zahar, 2005. 245 p.

VACARO, J.S. A construção do moderno e da loucura: mulheres no sanatório pinel de Pirituba (1929-1944). 2001. 63 p. Dissertação (Mestrado em História Social) - Departamento de História, Faculdade de Filosofia Letra e Ciências Humanas, Universidade de São Paulo. São Paulo, 2011.

WINNICOTT, D.W. Textos selecionados: da pediatria à psicanálise. São Paulo: Livraria Francisco Alves, 1993. p. 491-8.

WORMS, F. Les deux conceptis du soin. vie, medicine, relations morales. Esprit, p. 141-157, Janvier 2006.

ZACCAI-REYNERS, N. Respect, réciprocité et relations asymétriques. Quelques figures de la relation de soin. Esprit, p. 95-109, Janvier 2006.

\section{Nota}

${ }^{1}$ C.J. Muylaert participou da redação do artigo; revisão crítica relevante do conteúdo intelectual; e aprovação da versão final a ser publicada. A.O.A. Reis participou da concepção do projeto; análise e interpretação dos dados; redação do artigo; revisão crítica relevante do conteúdo intelectual e aprovação da versão final a ser publicada. P.S.S. Delfini participou da análise e interpretação dos dados; redação do artigo; revisão crítica relevante do conteúdo intelectual; e aprovação da versão final a ser publicada. 


\section{Gender differences among relatives of children and adolescents in mental health services}

The concept of gender points to social inequalities among men and women. This paper aims to describe and discuss, through gender identity theories, the role of relatives in the responsibility of providing physical, emotional care and financial support of Psychosocial Heath Centers for children and adolescents (CAPSi). Descriptive cross sectional study conducted in 19 CAPSi's in the State of São Paulo, Brazil, in 2009. Data were collected from a sample of 921 patients' records and submitted to descriptive statistical analysis. Mothers are the main responsible for the care in $56.9 \%(\mathrm{~N}=517)$ of cases, followed by grandparents, $7.8 \%(\mathrm{~N}=71)$ and fathers, $2.5 \%(\mathrm{~N}=23)$. Fathers are the main responsible for financial support in $20.3 \%(\mathrm{~N}=185)$ of cases, followed by mothers $8.9 \%(\mathrm{~N}=81)$. Great part of information about this subject was not found on patients' records (49.2\%). It was found that women are the main responsible by children care even when they are responsible for financial support. Data collected revealed the great importance of mother and women in care of children and adolescents in CAPSi and the hegemony of female gender as having the role of care. Gender bias is present in mental health field, and considering its importance, may be considered in the care of the population.

> Key words: mental health; gender identity; child care; family; adolescent. 